\title{
Clinical outcomes and prognostic factors of resected pancreatic neuroendocrine neoplasms: A single-center experience in China
}

\author{
KAIZHOU JIN ${ }^{1-3^{*}}$, GUOPEI LUO ${ }^{1-3^{*}}$, JIN XU $^{1-3^{*}}$, BO ZHANG ${ }^{1-3}$, CHEN LIU $^{1-3}$, \\ SHUNRONG JI ${ }^{1-3}$, LIANG LIU ${ }^{1-3}$, JIANG LONG ${ }^{1-3}$, QUANXING NI ${ }^{1-3}$ and XIANJUN YU ${ }^{1-3}$ \\ ${ }^{1}$ Department of Pancreatic Surgery, Fudan University Shanghai Cancer Center, Shanghai; ${ }^{2}$ Department of Oncology, \\ Shanghai Medical College, Fudan University; ${ }^{3}$ Pancreatic Cancer Institute, Fudan University, Shanghai 200032, P.R. China
}

Received August 14, 2016; Accepted November 28, 2016

DOI: $10.3892 / 01.2017 .5834$

\begin{abstract}
The aim of the present study was to investigate the clinical, pathological and prognostic characteristics of Chinese patients with resected pancreatic neuroendocrine neoplasms (p-NENs). Data from patients who were surgically treated and pathologically diagnosed with p-NENs at the Department of Pancreatic Oncology of the Fudan University Shanghai Cancer Center (Shanghai, China), between January 2003 and July 2015, were evaluated using univariate and multivariate analyses. A total of 162 patients with p-NENs met the criteria of the present study and were included in the analysis. Patients with poorly differentiated pancreatic neuroendocrine carcinoma (p-NEC) exhibited a significantly increased rate of lymph node metastasis, as compared with patients with grade $(\mathrm{G}) 1 / \mathrm{G} 2$ pancreatic neuroendocrine tumors (p-NETs) (62.5 vs. $20.5 \%, \mathrm{P}=0.003)$. Univariate analysis identified that the following factors led to decreased overall survival (OS): Lymph node metastasis $(\mathrm{P}=0.001$, vs. the absence of lymph node metastasis); distant metastasis ( $\mathrm{P}=0.043$, vs. the absence of distant metastasis); resection margin $\mathrm{R} 1 / \mathrm{R} 2$ ( $\mathrm{P}=0.030$, vs. R0 resection); NEC G3 (P<0.001, vs. NET G1). Following the multivariate analysis, NEC G3 remained a statistically significant risk factor $(\mathrm{HR}=12.593 ; 95 \% \mathrm{CI}, 3.476-45.622 ; \mathrm{P}<0.001$, vs. NET G1/G2). Furthermore, according to the proliferation marker protein Ki-67 staining index, assigning a grade using the proliferative index (G1, $\leq 5 \%$; G2, $>5-20 \%$; G3, >20\%) was more efficient for prognostic stratification compared with the European Neuroendocrine Tumor Society (Berlin, Germany)/World Health Organization (Geneva, Switzerland) 2010 grading classification. The present study indicated
\end{abstract}

Correspondence to: Professor Xianjun Yu, Department of Pancreatic Surgery, Fudan University Shanghai Cancer Center, 270 Dong An Road, Shanghai 200032, P.R. China

E-mail: yuxianjun@fudanpci.org

*Contributed equally

Key words: pancreas, neuroendocrine neoplasm, clinical outcome, prognostic factor that p-NEC was an important predictor of decreased OS in Chinese patients. Furthermore, a Ki-67 staining index of 5\% represented a more efficient value for the distinction between G1 and G2.

\section{Introduction}

Pancreatic neuroendocrine neoplasms (p-NENs) originate from pancreatic neuroendocrine cells, and have increased in incidence in American and Asian patients during the past 20 years $(1,2)$. To improve prognosis, Capella et al (3) developed a clinicopathological classification in 1995 according to clinical, radiographical and histopathological features. Based on this stratification, the World Health Organization (WHO; Geneva, Switzerland) published a classification system in 2000 that distinguishes well-differentiated endocrine tumors from well-differentiated and poorly differentiated endocrine carcinomas (4). Subsequently, in 2010, the WHO updated this classification system to reflect the proliferation marker protein Ki-67 index and mitotic count (5). In this revised classification system, p-NENs are classified as neuroendocrine tumor (NET) grade (G)1 (Ki-67 $\leq 2 \%)$, NET G2 (Ki-67 >2-20\%), neuroendocrine carcinoma (NEC) G3 (Ki-67 >20\%) and mixed adenoneuroendocrine carcinoma (5).

In 2006 the European Neuroendocrine Tumor Society (ENETS; Berlin, Germany), and in 2010 the American Joint Cancer Committee (Chicago, IL, USA), advocated tumor-node-metastasis (TNM) staging systems for the prognosis of p-NENs $(6,7)$, which referenced previous results from retrospective studies highlighting potential prognostic factors $(5,8)$. Conversely, according to hormone secretion status and clinical presentation, p-NENs are divided into functioning and non-functioning tumors (9). Non-functioning p-NENs may also secrete elevated amounts of hormones while remaining asymptomatic (10). Therefore, non-functioning p-NENs frequently present later in the course of the disease with symptoms resulting from local expansion or distant metastasis (11).

Surgical resection is the only potentially curative therapy for p-NENs, and palliative surgery is also an accepted course of action in cases of liver metastatic disease (12-15). With the development of surgical technology, improved long-term survival of patients with liver-metastatic p-NENs following 
cytoreductive surgery has also been recently reported (16). However, certain patients exhibit a short survival period following curative surgery and the significance of prognostic factors following surgical resection remains unclear (17). A unified standard to identify critical prognostic factors in $\mathrm{p}$-NENs remains to be performed. Therefore, in the present study the clinical characteristics and prognostic factors of Chinese patients with p-NENs following surgical treatment were analyzed, in order to identify potential risk factors and to detail the outcomes of p-NEN treatment.

\section{Materials and methods}

Patient selection. The present study retrospectively analyzed the medical records of a prospectively maintained database. Between January 2003 and July 2015, 162 patients were pathologically diagnosed with p-NEN and surgically treated at the Department of Pancreatic Oncology of the Fudan University Shanghai Cancer Center (Shanghai, China). The following eligibility criteria were applied (Fig. 1): i) Patients exhibited histologically confirmed p-NENs; ii) patients underwent surgery exclusively at the Fudan University Shanghai Cancer Center; iii) patients did not exhibit p-NET G3, which was defined as NET with high proliferative activity; iv) patients did not present with an unresectable primary tumor or have a history of other types of cancer.

Tumor characteristics. Patient demographics (age and gender), hormone secretion status (functioning or non-functioning) and tumor characteristics (size, location and presence of lymph node/distant metastasis) are presented in Table I. The WHO 2010 grading classifications and ENETS 2006 TNM staging system were used to assess the clinical outcomes of patients with p-NEN.

Follow-up and survival. Follow-up was performed via telephone, clinic visit, or outpatient visit between January 2015 and September 2015. Medical records of the included patients were reviewed to collect the following information: Age, gender, hormone secretion status, tumor size, tumor location, tumor invasion, lymphatic metastasis, distant metastasis, surgical approach, surgical margin status, ENETS 2006 TNM staging and WHO 2010 grading. A complete dataset was obtained following the exclusion of patients who succumbed to other factors during follow-up. The data were collected in a prospective manner.

Statistical analysis. Survival estimates were constructed using the Kaplan-Meier estimator method and survival curves were compared using the log-rank test. Differences between NET G1/G2 and NEC G3 were compared by the $\chi^{2}$ test. Univariate and multivariate Cox proportional hazards models were used to investigate the effects of several prognostic factors. Statistically significant factors following the univariate analysis were included in the multivariate analysis. Statistical analyses were performed using SPSS software (version 22.0; IBM SPSS, Armonk, NY, USA). $\mathrm{P}<0.05$ was considered to indicate a statistically significant difference.

\section{Results}

Patient characteristics. The patient clinicopathological data following diagnosis are summarized in Table I. The mean
Table I. Clinical, surgical and pathological characteristics of the study population $(n=162)$.

\begin{tabular}{lc}
\hline Characteristic & Total, $\mathrm{n}(\%)$ \\
\hline Mean age \pm SD, years & $51.2 \pm 12.6$ \\
Gender & \\
Male & $69(42.6)$ \\
Female & $93(57.4)$ \\
Hormone secretion status & \\
Functioning & $21(13.0)$ \\
Non-functioning & $141(87.0)$ \\
Mean tumor size \pm SD, cm & $4.1 \pm 2.8$ \\
Location & \\
Head & $64(39.5)$ \\
Body and tail & $95(58.6)$ \\
Multicentricity & $3(1.9)$ \\
Lymph node metastasis & $40(24.7)$ \\
Distant metastasis & $13(8.0)$ \\
Surgical approach & \\
PD/PPPD & $42(26.0)$ \\
DP & $88(54.3)$ \\
LP & $24(14.8)$ \\
TP & $8(4.9)$ \\
R0 resection & $147(90.7)$ \\
ENETS stage & \\
I & $40(24.7)$ \\
II & $77(47.5)$ \\
III & $32(19.8)$ \\
IV & $13(8.0)$ \\
2010 WHO grading classification & \\
NET G1 & $79(48.8)$ \\
NET G2 & $67(41.3)$ \\
NEC G3 & $16(9.9)$ \\
&
\end{tabular}

SD, standard deviation; PD, pancreatoduodenectomy; PPPD, pylorus-preserving PD; DP, distal pancreatectomy; LP, local resection of pancreatic tumor; TP, total pancreatectomy; ENETS, European Neuroendocrine Tumor Society; WHO, World Health Organization; NET, neuroendocrine tumor; G, grade; NEC, neuroendocrine carcinoma.

age ( \pm standard deviation) of the patients was $51.2 \pm 12.6$ years and $42.6 \%$ of the patients were male. A total of 141 patients $(87.0 \%)$ presented with a non-functioning tumor, whereas 21 patients $(13.0 \%)$ presented with a functioning tumor. The mean tumor diameter was $4.1 \pm 2.8 \mathrm{~cm}$. In 64 (39.5\%) patients, the primary disease site was the pancreatic head. A total of $40(24.7 \%)$ patients were pathologically confirmed to exhibit lymph node invasion, whereas $13(8.0 \%)$ patients exhibited distant metastases.

All patients with locoregional or metastatic disease received surgical treatment. Pancreatoduodenectomy, distal pancreatectomy and local resection of the pancreatic tumor were the most frequently performed surgical procedures. R0 
Table II. Surgical procedures and features of the patients with pancreatic neuroendocrine neoplasms $(n=162)$.

\begin{tabular}{lcc}
\hline Characteristic & $\begin{array}{c}\text { NET G1/G2 } \\
(\mathrm{n}=146)\end{array}$ & $\begin{array}{c}\text { NEC G3 } \\
(\mathrm{n}=16)\end{array}$ \\
\hline Tumor size, mean $\pm \mathrm{SD}, \mathrm{cm}$ & $4.05 \pm 2.75$ & $4.84 \pm 3.21$ \\
Location, $\mathrm{n}(\%)$ & & \\
Head & $59(40.4)$ & $5(31.2)$ \\
Body and tail & $84(57.5)$ & $11(68.8)$ \\
Multicentricity & $3(2.1)$ & $0(0.0)$ \\
Lymph node metastasis, $\mathrm{n}(\%)$ & $30(20.5)$ & $10(62.5)$ \\
Distant metastasis, $\mathrm{n}(\%)$ & $10(6.9)$ & $3(18.8)$ \\
Surgical approach, $\mathrm{n}(\%)$ & & \\
PD/PPPD & $38(36.0)$ & $4(25.0)$ \\
DP & $78(53.4)$ & $10(62.5)$ \\
LP & $24(13.7)$ & $0(0.0)$ \\
TP & $6(4.1)$ & $2(12.5)$ \\
R0 resection, $\mathrm{n}(\%)$ & $132(90.4)$ & $15(93.8)$ \\
ENETS stage, $\mathrm{n}(\%)$ & & \\
I & $39(26.7)$ & $1(6.3)$ \\
II & $72(49.3)$ & $5(31.2)$ \\
III & $25(17.1)$ & $7(43.8)$ \\
IV & $10(6.9)$ & $3(18.8)$ \\
\hline
\end{tabular}

NET, neuroendocrine tumor; NEC, neuroendocrine carcinoma; G, grade; SD, standard deviation; $\mathrm{PD}$, pancreatoduodenectomy; PPPD, pylorus-preserving PD; DP, distal pancreatectomy; LP, local resection of pancreatic tumor; TP, total pancreatectomy; ENETS, European Neuroendocrine Tumor Society.

resection was performed in $147(90.7 \%)$ patients, whereas the surgery was palliative in $15(9.3 \%)$ cases. There were $40(24.7 \%), 77(47.5 \%), 32(19.8 \%)$ and $13(8.0 \%)$ cases, classified as stage I, II, III and IV, respectively, according to the 2006 ENETS staging system. All 13 patients with stage IV p-NEN presented with a liver metastasis at the time of diagnosis.

The WHO 2010 grading classification was performed for all patients, yielding a distribution of 79 (48.8\%), 67 (41.3\%) and $16(9.9 \%)$, G1, G2 and G3 cases, respectively. Details of the surgical procedures and features are presented in Table II. Patients with p-NEC exhibited a significantly increased lymph node metastasis rate, compared with patients with $\mathrm{G} 1 / \mathrm{G} 2$ p-NETs (62.5 vs. $20.5 \%$, respectively, $\mathrm{P}=0.003$ ).

Survival analyses. The presence of lymphatic metastasis [hazard ratio $(\mathrm{HR})=4.802 ; 95 \%$ confidence interval $(\mathrm{CI})$, 1.824-12.645; $\mathrm{P}=0.001]$, distant metastasis $(\mathrm{HR}=3.267 ; 95 \%$ $\mathrm{CI}, 1.038-10.284 ; \mathrm{P}=0.043)$, and $\mathrm{R} 1 / \mathrm{R} 2$ resection $(\mathrm{HR}=3.277$; 95\% CI, 1.119-9.592; $\mathrm{P}=0.030)$ led to a decrease in overall survival (OS) compared with their absence (Table III). By contrast, gender, age, surgical approach, primary tumor size, hormone status, vessel invasion and perineural invasion had no significant effect on OS.

According to the WHO 2010 grading system, the differences in the survival time of patients classified as G1 and G3 $(\mathrm{HR}=28.134 ; 95 \% \mathrm{CI}, 6.219-127.272 ; \mathrm{P}<0.001)$ were statistically significant. However, a statistically significant difference between $\mathrm{G} 1$ and $\mathrm{G} 2$ was not observed $(\mathrm{HR}=2.605$; 95\% CI, 0.688-9.866; P=0.159). Furthermore, Ki-67 staining analysis defined a proliferative index of $\leq 5 \%$ as G1, between 5 and $20 \%$ as G2, and $>20 \%$ as G3, providing a more efficient stratification of Chinese patients with p-NENs (G1 vs. $\mathrm{G} 2, \mathrm{HR}=4.470$; 95\% CI, 1.273-15.699; $\mathrm{P}=0.019$; G1 vs. G3, $\mathrm{HR}=27.857$; 95\% CI, 7.058-109.944; $\mathrm{P}<0.001)$, as compared with the ENETS/WHO classification systems (Fig. 2).

In Table IV, when the Cox proportional hazards model was adjusted for grade, residual tumor classification, lymphatic metastasis and distant metastases, NEC G3 was a significant factor for poor prognosis on multivariate analysis $(\mathrm{HR}=12.593$; 95\% CI, 3.476-45.622; P<0.001, vs. NET G1/G2).

\section{Discussion}

Based on the results of the present study, four prognostic factors, including lymphatic metastasis, distant metastasis, $\mathrm{R} 1 / \mathrm{R} 2$ resection and $\mathrm{p}-\mathrm{NEC}$, predicted a poor prognosis following univariate analysis, and were subsequently used in multivariate analysis. p-NEC was an independent predictor of poor prognosis in patients with $\mathrm{p}-\mathrm{NEN}$ following multivariate analysis. In addition, p-NEC exhibited increased development of lymph node metastasis compared with G1/G2 p-NET.

Conversely, the present single-center study was not able to distinguish a difference in OS between G1 and G2 tumors, using $2 \%$ as the threshold value of the $\mathrm{Ki}-67$ index. The following grading index thresholds classified Chinese patients with p-NENs into three distinct survival groups more efficiently than the WHO 2010 grading classification: G1 $\leq 5 \%$; G2 >5-20\%; and G3>20\%.

The WHO 2010 grade classification system (5) was determined to be an independent predictor of clinical outcomes, thereby corroborating previously published studies $(18,19)$. However, Bettini et al (20) published conflicting results, in which the Ki-67 index was not demonstrated to have predictive value between G1 and G2 tumors. Furthermore, certain studies have demonstrated that a $\mathrm{Ki}-67$ index $>5 \%$ is the most efficient predictor of recurrence following resection for p-NENs $(21,22)$. In a multicenter study of 202 p-NEN cases, it was revealed that patients with a $\mathrm{Ki}-67$ index of $>5 \%$ had a notably unfavorable prognosis compared with patients with a Ki-67 index of $>2 \%$ (8). Rindi et al (23) also demonstrated that a $\mathrm{Ki}-67$ index of $5 \%$ is more efficient, compared with $2 \%$, for distinguishing between G1 and G2. In the receiver operating characteristic analysis of that study, the optimal threshold value for the prediction of tumor-associated mortality at five years was identified to be a Ki-67 index of $\geq 4.85$ (23). These findings suggest that a Ki-67 index of 5\% is a more efficient threshold value to distinguish between $\mathrm{G} 1$ and $\mathrm{G} 2$ in patients with p-NENs. Therefore, the revision of the Ki-67 index threshold value for classifying G1/G2 tumors from 2 to $5 \%$ is advised.

p-NEC exhibits a poor prognosis (24) and previous evidence has demonstrated the decreased survival rate of patients with p-NEC $(25,26)$. Furthermore, increased lymph node metastasis in $\mathrm{p}-\mathrm{NEC}$ was observed in the present study. This difference suggested increased malignant biological behavior in p-NEC, which was consistent with other studies $(19,27)$. Therefore, 
Table III. Univariate analysis of the clinical factors influencing the prognosis of patients with pancreatic neuroendocrine neoplasms.

\begin{tabular}{|c|c|c|c|c|}
\hline \multirow[b]{2}{*}{ Variable prognostic factor } & \multirow{2}{*}{$\begin{array}{l}\text { Mean survival } \\
\text { time, months }\end{array}$} & \multicolumn{3}{|c|}{ Univariate analysis } \\
\hline & & Hazard ratio & $95 \% \mathrm{CI}$ & P-value \\
\hline \multicolumn{5}{|l|}{ Gender } \\
\hline Male & 84 & - & - & - \\
\hline Female & 126 & 0.476 & $0.174-1.300$ & 0.147 \\
\hline \multicolumn{5}{|l|}{ Age, years } \\
\hline$\leq 51$ & 109 & - & - & - \\
\hline$>51$ & 91 & 0.996 & $0.384-2.587$ & 0.994 \\
\hline \multicolumn{5}{|l|}{ Surgical approaches } \\
\hline PD/PPPD & 87 & - & - & - \\
\hline DP & 116 & 0.789 & $0.263-2.368$ & 0.672 \\
\hline LP & 96 & 0.611 & $0.118-3.169$ & 0.558 \\
\hline $\mathrm{TP}$ & 44 & 1.723 & $0.196-15.154$ & 0.624 \\
\hline \multicolumn{5}{|l|}{ Primary tumor size, $\mathrm{cm}$} \\
\hline$\leq 4$ & 118 & - & - & - \\
\hline$>4$ & 88 & 1.516 & $0.570-4.029$ & 0.404 \\
\hline \multicolumn{5}{|l|}{ Hormone status } \\
\hline Functioning & 56 & - & - & - \\
\hline Non-functioning & 111 & 1.792 & $0.231-13.890$ & 0.576 \\
\hline \multicolumn{5}{|l|}{ Lymph node metastasis } \\
\hline No & 120 & - & - & - \\
\hline Yes & 71 & 4.802 & $1.824-12.645$ & $0.001^{\mathrm{a}}$ \\
\hline \multicolumn{5}{|l|}{ Vessel invasion } \\
\hline No & 113 & - & - & - \\
\hline Yes & 81 & 2.380 & $0.911-6.217$ & 0.077 \\
\hline \multicolumn{5}{|l|}{ Perineural invasion } \\
\hline No & 113 & - & - & - \\
\hline Yes & 84 & 1.445 & $0.531-3.937$ & 0.471 \\
\hline \multicolumn{5}{|l|}{ Distant metastasis } \\
\hline No & 115 & - & - & - \\
\hline Yes & 56 & 3.267 & $1.038-10.284$ & $0.043^{\mathrm{a}}$ \\
\hline \multicolumn{5}{|l|}{ Resection } \\
\hline R0 & 115 & - & - & - \\
\hline $\mathrm{R} 1 / \mathrm{R} 2$ & 62 & 3.277 & $1.119-9.592$ & $0.030^{\mathrm{a}}$ \\
\hline \multicolumn{5}{|l|}{ Ki-67 (ENETS/WHO 2010) } \\
\hline$\leq 2$ & 126 & - & - & - \\
\hline$>2-20$ & 88 & 2.605 & $0.688-9.866$ & 0.159 \\
\hline$>20$ & 21 & 28.134 & $6.219-127.272$ & $<0.001^{\mathrm{a}}$ \\
\hline \multicolumn{5}{|l|}{ Ki-67 modified } \\
\hline$\leq 5$ & 128 & - & - & - \\
\hline$>5-20$ & 80 & 4.470 & $1.273-15.699$ & $0.019^{\mathrm{a}}$ \\
\hline$>20$ & 21 & 27.857 & $7.058-109.944$ & $<0.001^{\mathrm{a}}$ \\
\hline
\end{tabular}

radical surgery with lymphadenectomy is typically recommended for the treatment of localized p-NEC (28).
There were several limitations to the present study. The mean duration of follow-up was 30.3 months, which was 


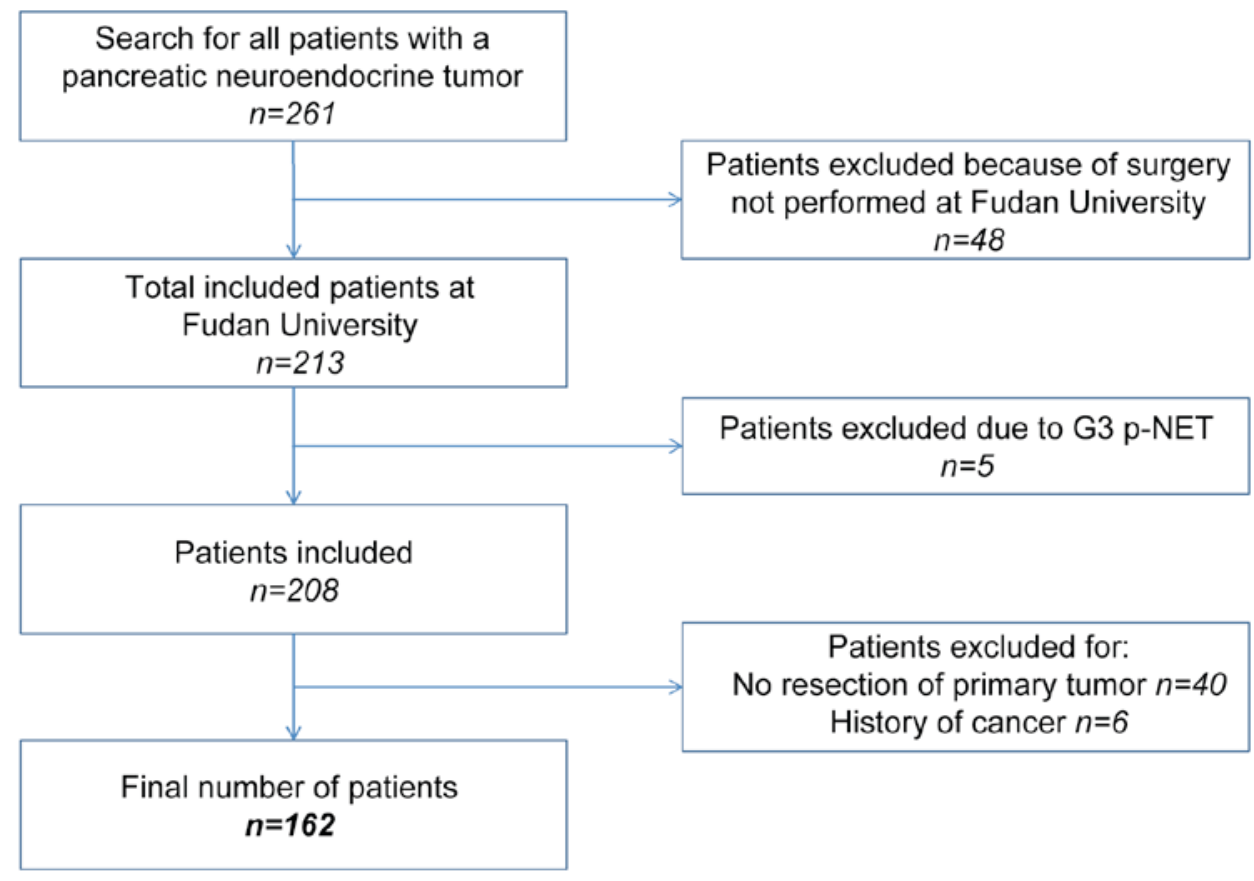

Figure 1. Flow chart of the process of patient selection. G, grade; p-NET, pancreatic neuroendocrine tumor.

Table IV. Multivariate analysis of the clinical factors influencing the prognosis of patients with pancreatic neuroendocrine neoplasms.

\begin{tabular}{lccc}
\hline \multirow{2}{*}{$\begin{array}{l}\text { Variable } \\
\text { prognostic factor }\end{array}$} & \multicolumn{3}{c}{ Multivariate analysis } \\
\cline { 2 - 4 } & Hazard ratio & $95 \%$ CI & P-value \\
\hline Lymph invasion & & & - \\
No & - & - & - \\
Yes & 2.904 & $0.970-8.697$ & 0.057 \\
Distant metastasis & & & - \\
No & - & - & - \\
Yes & 2.460 & $0.391-15.492$ & 0.338 \\
Resection & & & \\
R0 & - & - & - \\
R1/R2 & 3.695 & $0.696-19.625$ & 0.125 \\
Tumor grade & & & - \\
NET G1/G2 & - & - & - \\
NEC G3 & 12.593 & $3.476-45.622$ & $<0.001^{\mathrm{a}}$ \\
\hline${ }^{\text {aStatistically significant. }}$ & & & \\
\hline
\end{tabular}

shorter compared with other p-NEN studies. The use of an increased sample size is necessary to confirm potential prognostic factors associated with an obvious decrease in survival. Furthermore, relapse-free survival was not analyzed due to the limitation of data integrity, and more effective models are essential in order to reduce loss to follow-up.

In conclusion, the WHO grade classification is a key prognostic factor, while p-NEC is a crucial predictor of poorer OS in Chinese patients with p-NENs. A Ki-67 staining index of $5 \%$ is a more efficient threshold value for the identification of
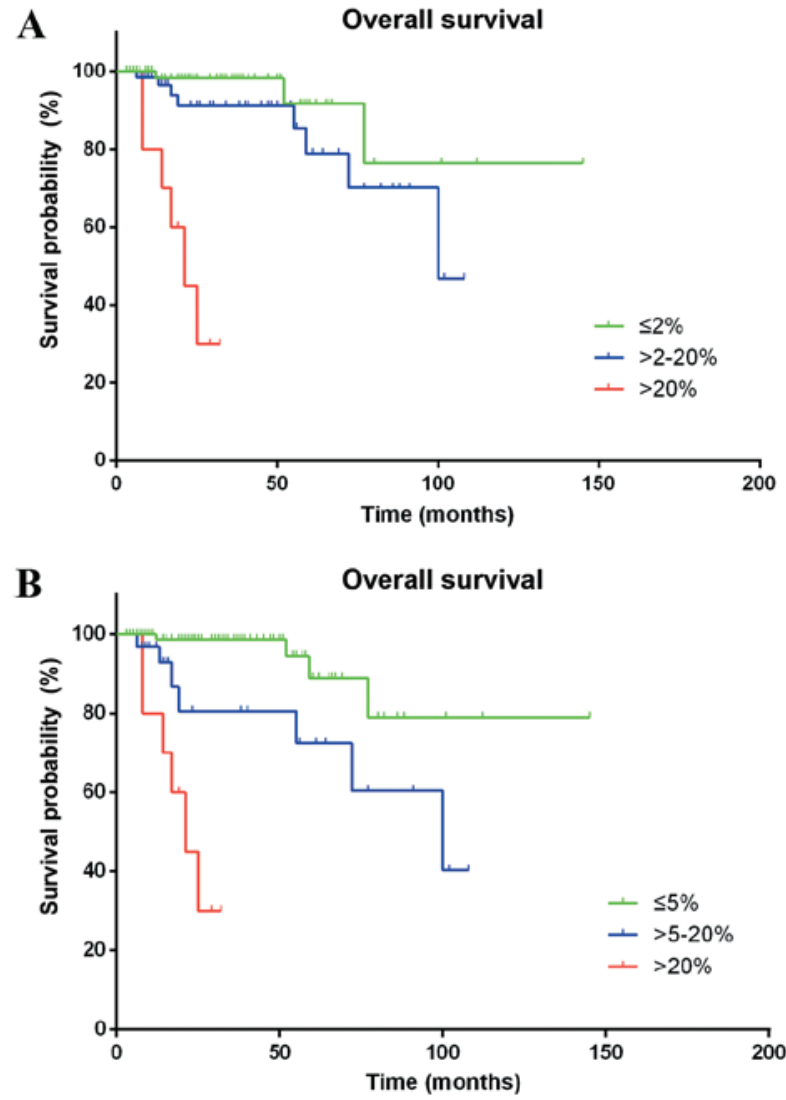

Figure 2. Kaplan-Meier estimator curves of cumulative survival rates. (A) Stratified by the World Health Organization 2010 grading system. (B) Stratified by proliferation marker protein Ki-67 index.

G1 and G2. Therefore, the results of the present study suggest that the threshold for classifying G1/G2 tumors be revised from 2 to $5 \%$ in patients with p-NENs. 


\section{Acknowledgements}

The present study was supported in part by the Sino-German Center (grant no. GZ857), the Science Foundation of Shanghai (grant no. 13ZR1407500) and the National Science Foundation of China (grant no. 81101807).

\section{References}

1. Yao JC, Hassan M, Phan A, Dagohoy C, Leary C, Mares JE, Abdalla EK, Fleming JB, Vauthey JN, Rashid A and Evans DB: One hundred years after 'carcinoid': Epidemiology of and prognostic factors for neuroendocrine tumors in 35,825 cases in the United States. J Clin Oncol 26: 3063-3072, 2008.

2. Tsai HJ, Wu CC, Tsai CR, Lin SF, Chen LT and Chang JS: The epidemiology of neuroendocrine tumors in Taiwan: A nation-wide cancer registry-based study. PLoS One 8: e62487, 2013.

3. Capella C, Heitz PU, Höfler H, Solcia E and Klöppel G: Revised classification of neuroendocrine tumours of the lung, pancreas and gut. Virchows Arch 425: 547-560, 1995.

4. Solcia E, Klöppel G and Sobin LH: Histological Typing of Endocrine Tumors. WHO International Histological Classification of Tumors (Springer, Berlin, Germany). 2000.

5. Rindi GAR, Bosman FT ea: Nomenclature and classification of neuroendocrine neoplasms of the digestive system. In: Bosman T, Carneiro F, Hruban R, et al. (eds). In: Bosman T, Carneiro F, Hruban R, et al (eds). WHO Classification of Tumours of the Digestive System. 4th edition Lyon, France: International Agency for Research on Cancer (IARC) 3: 417, 2010.

6. Rindi G, Klöppel G, Alhman H, Caplin M, Couvelard A, de Herder WW, Erikssson B, Falchetti A, Falconi M, Komminoth $\mathrm{P}$, et al: TNM staging of foregut (neuro)endocrine tumors: A consensus proposal including a grading system. Virchows Arch 449: 395-401, 2006.

7. Edge SBBDR, Compton CC ea. AJCC Cancer Staging Manual. New York, NY. Springer 2010.

8. Panzuto F, Boninsegna L, Fazio N, Campana D, Pia Brizzi M, Capurso G, Scarpa A, De Braud F, Dogliotti L, Tomassetti P, et al: Metastatic and locally advanced pancreatic endocrine carcinomas: Analysis of factors associated with disease progression. J Clin Oncol 29: 2372-2377, 2011.

9. Kulke MH, Bendell J, Kvols L, Picus J, Pommier R and Yao J: Evolving diagnostic and treatment strategies for pancreatic neuroendocrine tumors. J Hematol Oncol 4: 29, 2011.

10. Dixon E and Pasieka JL: Functioning and nonfunctioning neuroendocrine tumors of the pancreas. Curr Opin Oncol 19: 30-35, 2007.

11. Cheema A, Weber J and Strosberg JR: Incidental detection of pancreatic neuroendocrine tumors: An analysis of incidence and outcomes. Ann Surg Oncol 19: 2932-2936, 2012.

12. Haugvik SP, Janson ET, österlund P,Langer SW,Falk RS, Labori KJ, Vestermark LW, Grønbæk H, Gladhaug IP and Sorbye H: Surgical treatment as a principle for patients with high-grade pancreatic neuroendocrine carcinoma: A nordic multicenter comparative study. Ann Surg Oncol 23: 1721-1728, 2016.

13. Kim MJ, Choi DW, Choi SH, Heo JS, Park HJ, Choi KK, Jang KT and Sung JY: Surgical strategies for non-functioning pancreatic neuroendocrine tumours. Br J Surg 99: 1562-1568, 2012.

14. Hill JS, McPhee JT, McDade TP, Zhou Z, Sullivan ME, Whalen GF and Tseng JF: Pancreatic neuroendocrine tumors: The impact of surgical resection on survival. Cancer 115: 741-751, 2009.
15. Franko J, Feng W, Yip L, Genovese E and Moser AJ: Non-functional neuroendocrine carcinoma of the pancreas: Incidence, tumor biology, and outcomes in 2,158 patients. J Gastrointest Surg 14: 541-548, 2010.

16. Cusati D, Zhang L, Harmsen WS, Hu A, Farnell MB, Nagorney DM, Donohue JH, Que FG, Reid-Lombardo KM and Kendrick ML: Metastatic nonfunctioning pancreatic neuroendocrine carcinoma to liver: Surgical treatment and outcomes. J Am Coll Surg 215: 117-125, 2012.

17. Ekeblad S, Skogseid B, Dunder K, Oberg K and Eriksson B: Prognostic factors and survival in 324 patients with pancreatic endocrine tumor treated at a single institution. Clin Cancer Res 14: 7798-7803, 2008

18. Ballian N, Loeffler AG, Rajamanickam V, Norstedt PA, Weber SM and Cho CS: A simplified prognostic system for resected pancreatic neuroendocrine neoplasms. HPB (Oxford) 11: 422-428, 2009.

19. Fischer L, Bergmann F, Schimmack S, Hinz U, Prieß S, Müller-Stich BP, Werner J, Hackert T and Büchler MW: Outcome of surgery for pancreatic neuroendocrine neoplasms. Br J Surg 101: 1405-1412, 2014.

20. Bettini R, Boninsegna L, Mantovani W, Capelli P, Bassi C, Pederzoli P, Delle Fave GF, Panzuto F, Scarpa A and Falconi M: Prognostic factors at diagnosis and value of WHO classification in a mono-institutional series of 180 non-functioning pancreatic endocrine tumours. Ann Oncol 19: 903-908, 2008.

21. Boninsegna L, Panzuto F, Partelli S, Capelli P, Delle Fave G, Bettini R, Pederzoli P, Scarpa A and Falconi M: Malignant pancreatic neuroendocrine tumour: Lymph node ratio and Ki67 are predictors of recurrence after curative resections. Eur J Cancer 48: 1608-1615, 2012.

22. Khan MS, Luong TV, Watkins J, Toumpanakis C, Caplin ME and Meyer T: A comparison of Ki-67 and mitotic count as prognostic markers for metastatic pancreatic and midgut neuroendocrine neoplasms. Br J Cancer 108: 1838-1845, 2013

23. Rindi G, Falconi M, Klersy C, Albarello L, Boninsegna L, Buchler MW, Capella C, Caplin M, Couvelard A, Doglioni C, et al: TNM staging of neoplasms of the endocrine pancreas: Results from a large international cohort study. J Natl Cancer Inst 104: 764-777, 2012

24. Vélayoudom-Céphise FL, Duvillard P, Foucan L, Hadoux J, Chougnet CN, Leboulleux S, Malka D, Guigay J, Goere D, Debaere T, et al: Are G3 ENETS neuroendocrine neoplasms heterogeneous. Endocr Relat Cancer 20: 649-657, 2013.

25. Hashim YM, Trinkaus KM, Linehan DC, Strasberg SS, Fields RC, Cao D and Hawkins WG: Regional lymphadenectomy is indicated in the surgical treatment of pancreatic neuroendocrine tumors (PNETs). Ann Surg 259: 197-203, 2014.

26. Strosberg JR, Cheema A, Weber J, Han G, Coppola D and Kvols LK: Prognostic validity of a novel american joint committee on cancer staging classification for pancreatic neuroendocrine tumors. J Clin Oncol 29: 3044-3049, 2011.

27. Wong J, Fulp WJ, Strosberg JR, Kvols LK, Centeno BA and Hodul PJ: Predictors of lymph node metastases and impact on survival in resected pancreatic neuroendocrine tumors: A single-center experience. Am J Surg 208: 775-780, 2014.

28. Garcia-Carbonero R, Sorbye H, Baudin E, Raymond E, Wiedenmann B, Niederle B, Sedlackova E, Toumpanakis C, Anlauf M, Cwikla JB, et al: ENETS consensus guidelines for high-grade gastroenteropancreatic neuroendocrine tumors and neuroendocrine carcinomas. Neuroendocrinology 103: 186-194, 2016. 